\title{
CINEMA ACOUSTICS AND TELEVISION RECEIVERS
}

\begin{abstract}
$\mathrm{A}^{\mathrm{s}}$ $S$ was mentioned in the issue of NATURE of February 15, the Institution of Electrical Engineers now publishes extended abstracts only of papers in Part I of its Journal, the full papers being issued later in either Part II or Part III, according as the subject-matter of the paper is appropriately classified as power or communication engineering. Part III includes the Proceedings of the Wireless Section of the Institution, and the September issue of this part contains three related papers in full.
\end{abstract}

The first of these is by Messrs. C. A. Mason and J. Moir, and is entitled "Acoustics of Cinema Auditoria", and the paper describes the results of investigations made to discover the reasons for the difference in performance of sound reproduced by identical equipment in apparently similar cinemas. It was apparent from the preliminary investigations in four different theatres that overall frequency characteristics and reverberation times were not the controlling factors for good sound quality, which is defined in terms of both intelligibility and intimacy, the latter term being used for the impression conveyed to the audience that the sound actually proceeds from the picture on the screen. Experiments were then conducted with an impulse source com. prising a short train of waves of a fixed audio-frequency emitted through the loud-speakers. By means of a microphone and cathode-ray tube equipment, measurements were then made of the paths taken by the reflected sound in the auditorium.

The results showed first that there was little distortion in the amplifiers and loud-speakers, but that the sound received in the auditorium comprised a direct pulse and some reflected pulses, the number and magnitudes of which depended upon the design and shape of the auditorium. The authors conclude from their investigation that while the reverberation-time of a cinema should approach the optimum value for good intelligibility, it is also necessary that the shape of the auditorium should be such as to avoid reflected-sound paths differing greatly in length from the direct path. The paper concludes with a detailed discussion of the practical design of an auditorium with good intimacy, as well as intelligibility, properties.

The second paper is by B. J. Edwards, and is entitled "The Design of Television Receiving Apparatus". This paper comprises a detailed description of the design of a particular form of receiving equip. ment for television reception to the standards provided for by the B.B.C. transmitter at Alexandra Palace prior to the outbreak of war in 1939 . In portraying the detailed electrical and mechanical features of the design, the author shows the fundamental reasons for the adoption and evolution of the particular methods employed. For example, the advantages and disadvantages of electric and magnetic deflexion in cathode ray tubes are demonstrated, and in justification of the adoption of the fully magnetic tube, it is claimed that it gives repro. duction of a television picture of superior definition and brightness, and that it lends itself to a slightly more economical design of circuit.

In the concluding portion of the paper, some speculation is given to the trend of design for television reception. The possibility of a general increase in the carrier frequency up to the order of $100 \mathrm{Mc}$./sec. is envisaged, and this will bring with it certain problems in the attainment of selectivity for reception; also the general demand for a larger picture is likely to result in the development of the small projection type of cathode-ray tube, giving a picture of high intensity of illumination, in association with a suitable projection lens constructed possibly of a suitable plastic material at a favourable price.

The third paper under consideration is of a theoretical nature. It is on "Electromagnetic Waves in Metal Tubes of Rectangular Cross-Section" and is contributed by J. Kemp. The attenuation of electric waves propagated through the interior of metal tubes of rectangular cross-section is calculated by the familiar telephone transmission formulæ, instead of by the usual classical method first used for this problem by Lord Rayleigh. The present author states that the characteristic advantages of the former method are its simplicity and the directness with which the final results emerge. The method reveals the existence of a link between two seemingly disjointed branches of telecommunication, first the classical circuit comprising a 'go' and 'return' path, and second, the transmission of waves through a hollow metal tube without a return path in the convesntional sense.

\section{DRUGS FROM THE EMPIRE}

$\mathrm{T}$ HE Imperial Institute has reprinted as a booklet an article from the Bulletin of the Institute by Dr. M. Ashby*, surveying the possibilities of pro. ducing in the Empire drugs hitherto obtained from Central Europe. Dr. Ashby has done his work well and the publication is timely. There has been much unco-ordinated and misdirected activity in the field of drug supplies and this paper helps to set the problem in perspective. Two basic considerations have tended to be forgotten by enthusiasts who have sought to encourage new cultivation. One is that

- War-Time Drug Supplies and Empire Production. By Dr. M. Ashby. Pp. 39. (Imperial Institute, Iondon. S.W.7.) 18. net. energies should be directed to essential drugs only; the other that to the commercial grower, the problem is a business problem as well as a patriotic one. By reason of lack of early official guidance, many enthusiastic amateurs in Great Britain are wasting both energy and ground in the collection and cultivation of plants having the weakest of claims to being essential in therapeutics. Dandelion, coltsfoot, camomile and the leaves of the lime are a few examples. They command good prices, but those who grow or harvest them would do better to concentrate on potatoes or onions. Belladonna, hyos. cyamus, stramonium, digitalis and perhaps colchicum 